\title{
Type three secretion system-mediated escape of Burkholderia pseudomallei into the host cytosol is critical for the activation of NFKB
}

Boon Eng Teh ${ }^{1}$, Christopher Todd French ${ }^{2}$, Yahua Chen ${ }^{1}$, Isabelle Gek Joo Chen ${ }^{1}$, Ting-Hsiang Wu ${ }^{3,4}$, Enrico Sagullo ${ }^{3}$, Pei-Yu Chiou ${ }^{4,5}$, Michael A Teitell ${ }^{3,5,6,7,8}$, Jeff F Miller ${ }^{2,5,8}$ and Yunn-Hwen Gan ${ }^{1, *^{*}}$

\begin{abstract}
Background: Burkholderia pseudomallei is the causative agent of melioidosis, a potentially fatal disease endemic in Southeast Asia and Northern Australia. This Gram-negative pathogen possesses numerous virulence factors including three "injection type" type three secretion systems (T3SSs). B. pseudomallei has been shown to activate NFKB in HEK293T cells in a Toll-like receptor and MyD88 independent manner that requires T3SS gene cluster 3 (T3SS3 or T3SS ${ }_{\text {Bsa }}$ ). However, the mechanism of how T3SS3 contributes to NFKB activation is unknown.

Results: Known T3SS3 effectors are not responsible for NFKB activation. Furthermore, T3SS3-null mutants are able to activate NFKB almost to the same extent as wildtype bacteria at late time points of infection, corresponding to delayed escape into the cytosol. NFkB activation also occurs when bacteria are delivered directly into the cytosol by photothermal nanoblade injection.
\end{abstract}

Conclusions: T3SS3 does not directly activate NFKB but facilitates bacterial escape into the cytosol where the host is able to sense the presence of the pathogen through cytosolic sensors leading to NFKB activation.

\section{Background}

Burkholderia pseudomallei, the causative agent of melioidosis, is a highly versatile Gram-negative bacterium capable of invading epithelial cells [1] as well as surviving in macrophages [2]. Common routes of entry for $B$. pseudomallei are via cutaneous inoculation, inhalation, or ingestion. Melioidosis is endemic in Southeast Asia, Northern Australia and other tropical regions [3], and clinical outcome is relatively dependent on the size of the inoculum and the existence of predisposing risk factors [4]. B. pseudomallei possesses an extensive arsenal of recognized virulence determinants, including three "injection type" type III secretion systems (T3SSs) and six type VI secretion systems (T6SSs). T3SSs are present in many Gram-negative pathogens and translocate "effector" proteins into eukaryotic host cells to alter their cellular

\footnotetext{
* Correspondence: yunn_hwen_gan@nuhs.edu.sg

'Department of Biochemistry, Yong Loo Lin School of Medicine, National

University of Singapore, Singapore 117597, Singapore

Immunology Program, National University of Singapore, Singapore 117597,

Singapore

Full list of author information is available at the end of the article
}

response. In B. pseudomallei, only T3SS3 has been implicated in animal pathogenesis [5,6], while T3SS1 and -2 are predicted to mediate interactions with plants [7]. T3SS3 has also been shown to be important for bacterial escape from phagosomes or endosomes into the host cytosol [8,9] and caspase 1-induced pyroptosis [10].

Since T3SS is a virulence determinant utilized by a variety of Gram-negative species, mammalian hosts have evolved sensors to detect the presence of T3SSs during pathogenesis. In macrophages, the T3SS of Salmonella typhimurium, Shigella flexneri, B. pseudomallei, Pseudomonas aeruginosa, enterohemorrhagic and enteropathogenic $E$. coli trigger a proinflammatory response mediated by the NLRC4 inflammasome and subsequent activation of caspase 1 [11]. In Yersinia, it is unclear whether caspase 1 activation is triggered by the translocon pore or via unknown T3SS-related factors [12]. In addition to detection by the inflammasome machinery, Yersinia [13] and Salmonella [14] can be detected by NFKB in a Toll-like receptor (TLR) and MyD88 independent manner that is reliant on T3SS, revealing another possible mechanism whereby T3SS can be detected by host epithelial cells 
which lack inflammasome machinery. Using human embryonic kidney cells (HEK293T), which are epithelial cells that lack TLR 2, 4 and 9 expression but expresses low levels of TLR 5 and $7[15,16]$, we have previously shown that B. pseudomallei stimulates $\mathrm{NF} \mathrm{B}$ independently of TLRs and MyD88, leading to the production of IL-8. $\mathrm{NF} \mathrm{KB}$ activation required bacterial internalization and a functional T3SS3 [17]. However, it is unclear whether $\mathrm{NF} \kappa \mathrm{B}$ activation is triggered by T3SS3 effector proteins, by components of the T3SS secretion apparatus itself, or indirectly via additional T3SS3-mediated processes.

Our goal is to determine how T3SS3 contributes to NFKB activation in the absence of TLR, MyD88 and inflammasome signalling using HEK293T epithelial cells as a model system. We show that T3SS3-mediated endosome escape is required for $\mathrm{NF} \mathrm{KB}$ activation and occurs independently of known T3SS3 effector proteins. Using a photothermal nanoblade to directly place bacteria into the cytoplasm, we show that cytosolic localization is sufficient to activate NFkB. Thus, B. pseudomallei T3SS3 is not directly detected by the host $\mathrm{NF}_{\kappa} \mathrm{B}$ pathway but is instead responsible for bacterial escape from vacuolar compartments subsequently leading to the activation of cytosolic sensors.

\section{Results}

TLR-independent NFKB activation by B. pseudomallei is dependent on the activity of T3SS3 but not known T3SS3 effector proteins

We had previously shown that activation of $\mathrm{NF}_{\kappa} \mathrm{B}$ in HEK293T cells by B. pseudomallei was not dependent on host TLR and MyD88 signalling but required a functional bacterial T3SS3 [17]. Here, we first investigate whether B. pseudomallei T3SS1 and T3SS2 contribute to $\mathrm{NF} \kappa \mathrm{B}$ activation, or if it is a specific consequence of T3SS3 activity. Derivatives of B. pseudomallei strain KHW containing deletions of the entire T3SS3, T3SS2 or T3SS1 gene clusters were constructed by allelic exchange. HEK293T cells that were transiently transfected with the NFKBSEAP (secreted embryonic alkaline phosphatase) reporter system were infected with wildtype KHW or mutant strain, and assayed for $\mathrm{NF}_{\mathrm{K} B}$ activation $6 \mathrm{hr}$. later. As shown in Figure $1 \mathrm{~A}$, infection with the $\triangle \mathrm{T} 3 \mathrm{SS} 3$ strain showed reduced NFKB activation in contrast to the $\triangle \mathrm{T} 3 \mathrm{SS} 1$ and $\triangle \mathrm{T} 3 \mathrm{SS} 2$ mutant derivatives, which led to robust activation comparable to wildtype bacteria. As the $\triangle \mathrm{T} 3 \mathrm{SS} 3$ mutant was unable to replicate as well as wildtype KHW and the other mutants (Figure 1B), the lack of $\mathrm{NF}_{\mathrm{B}} \mathrm{B}$ activation could be due to lower bacterial numbers. Furthermore, it is known that complete deletion of T3SS3 also inactivates T6SS1 due to removal of T6SS1 regulatory loci located in the T3SS3 gene cluster [18]. To determine whether NFkB activation is dependent on the activity of T3SS3 or T6SS1, a strain containing an in-frame deletion in bsaM, which

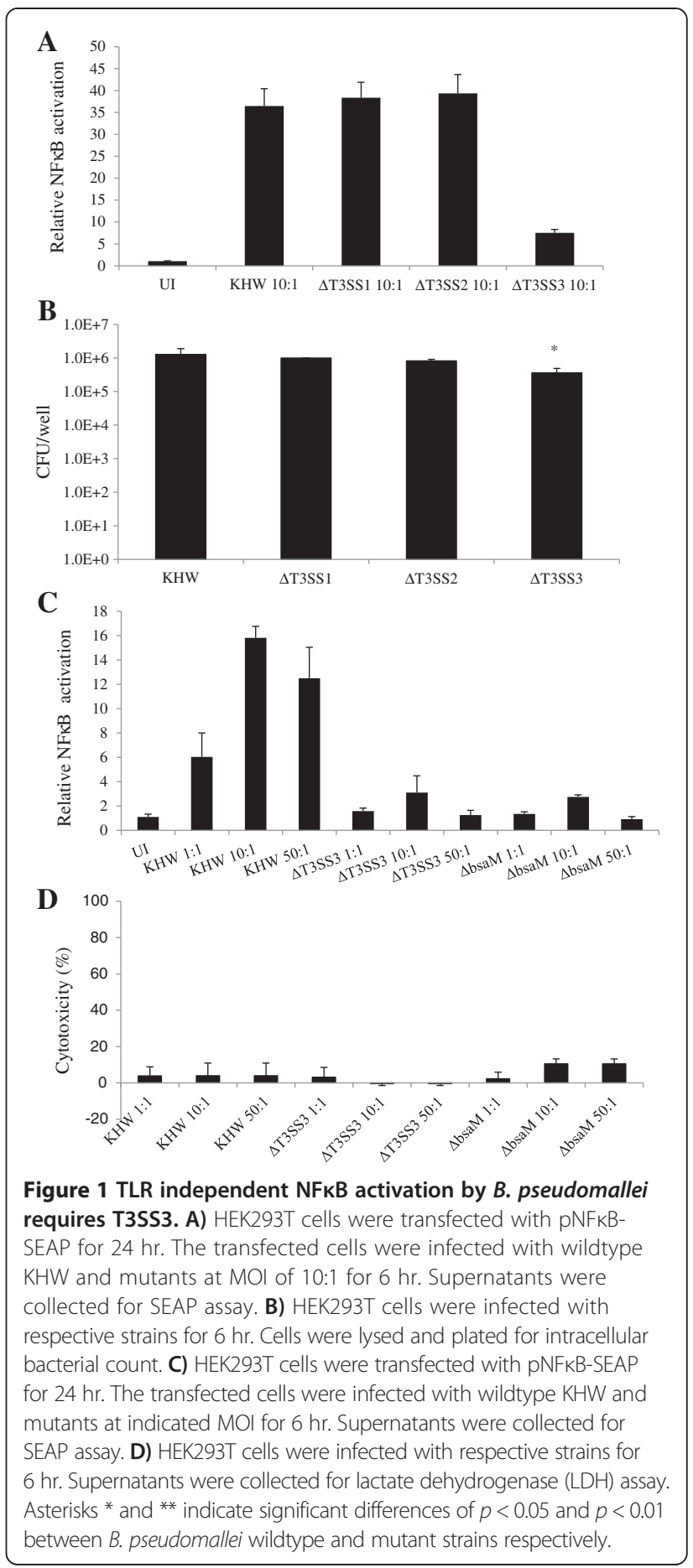

encodes an inner membrane ring component of T3SS3 that is essential for function, was assayed in parallel [19]. The $\triangle b s a M$ mutation does not affect T6SS regulatory loci that are present in the T3SS3 gene cluster. The results in Figure $1 \mathrm{C}$ demonstrate that infection with the $\triangle b s a M$ and the $\Delta \mathrm{T} 3 S S 3$ mutants leads to equivalently low levels of $\mathrm{NF} B \mathrm{~B}$ activation compared to wildtype KHW, even at high multiplicity of infection 
(MOI). All subsequent experiments were then performed with the $\Delta b s a M$ mutant instead of the $\Delta \mathrm{T} 3 \mathrm{SS} 3$ mutant. The amount of bacterial-induced cellular cytotoxicity was very low (10\% or less) and comparable across all strains and MOIs (Figure 1D), showing that difference in $\mathrm{NF}_{\kappa} \mathrm{B}$ activation is not due to differing levels of cell death. The lack of increase in NFKB activation at MOI of 50:1 could be due to NFkB suppression mediated by the presence of TssM in the strains, as we had previously reported [20].

The role of T3SS is to translocate effector proteins into the eukaryotic cell interior. Unlike the T3SSs of some other pathogenic species such as Salmonella and Shigella, B. pseudomallei T3SS3 possesses only three known effectors; BopA [21], BopC [22], and BopE [23]. When cells were infected with $\triangle b o p A, \triangle b o p C$ or $\triangle b o p E$ strains and NFKB activation was measured at $6 \mathrm{hr}$. after infection, no significant difference was observed compared to wildtype KHW. In the case of the $\triangle b s a M$ mutant, activation was minimal as expected, whereas the $\triangle$ bopACE triple effector mutant showed a slight reduction in NFkB activation (5.4 fold) compared to wildtype bacteria (6.4 fold) (Figure 2A). Moreover, the $\Delta b s a M$ strain exhibited an approximately 5.5-fold reduction in the numbers of intracellular bacteria compared to wildtype bacteria at the same $6 \mathrm{hr}$. time point, while $\triangle b o p A C E$ was only slightly (2 fold) reduced (Figure $2 \mathrm{~B}$ ), corresponding with their respective abilities to activate NFKB shown in Figure 2A. Thus, lower $\mathrm{NF}_{\mathrm{K}} \mathrm{B}$ activation is likely due to lower replication rates of the $\triangle b s a M$ and $\triangle b o p A C E \mathrm{mu}-$ tants, and does not seem to be contributed by the known T3SS3 effectors.

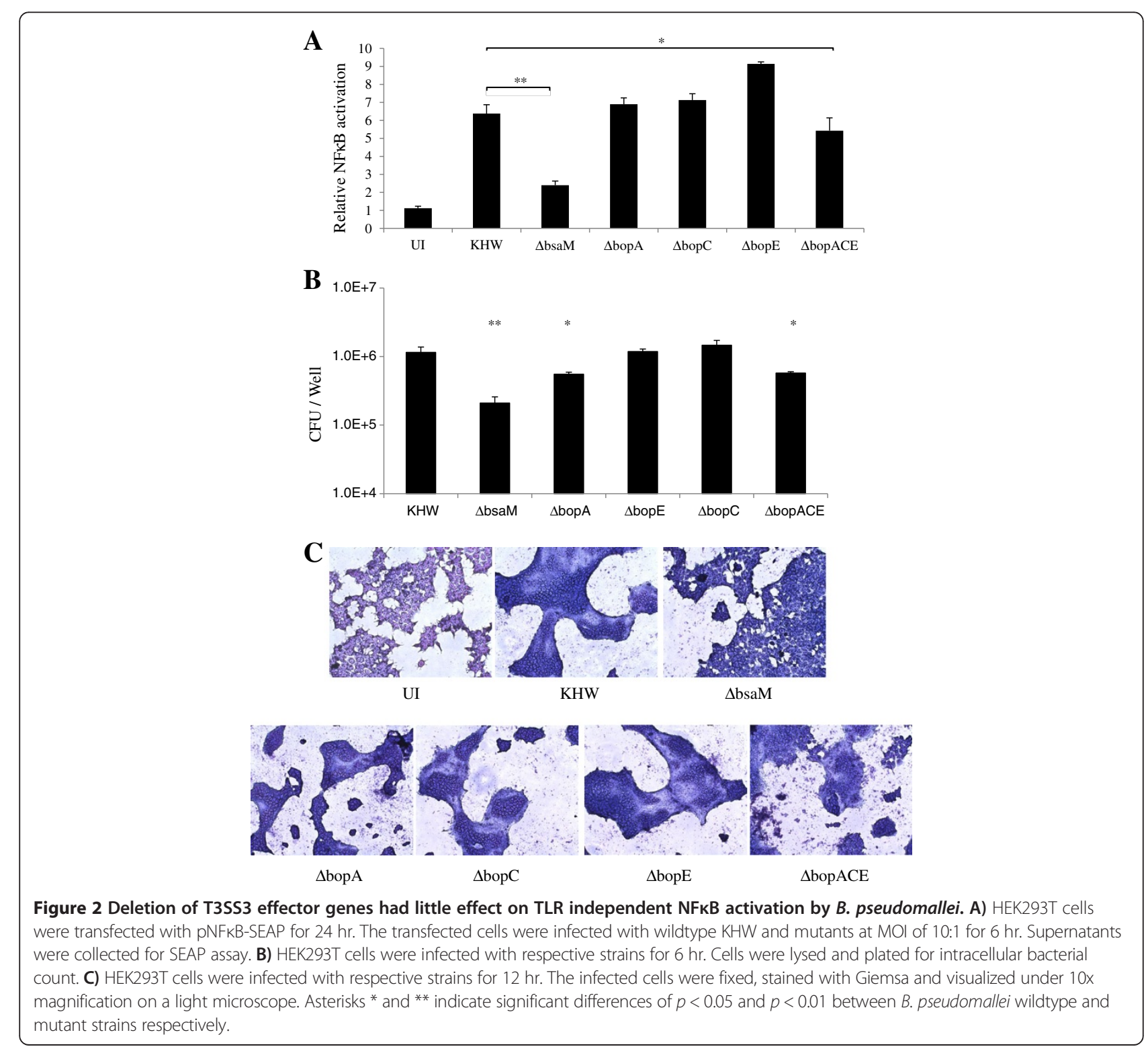


T3SS3 does not facilitate invasion of bacteria into cells but rather promotes their subsequent escape from endocytic vesicles [24]. Therefore, defective endosome escape by mutants may provide an explanation for their reduced replication and inability to activate NFkB. Thus, we examined whether the ability of these mutants to activate $\mathrm{NF}_{\kappa} \mathrm{B}$ correlate with their ability to escape from the endosome. The formation of multinucleated giant cells (MNGC) at 10-12 hr. following infection was utilized as a measure of endosome escape, since it requires the activity of T6SS1 and only occurs if bacteria have escaped from endocytic vesicles into the cytosol [18,24]. We examined the formation of MNGC at $12 \mathrm{hr}$. post infection of the single and triple effector mutants in comparison with wildtype $\mathrm{KHW}$ and the escape-deficient $\triangle$ bsaM (Figure 2C). All strains could induce MNGC at this time-point except for $\triangle b s a M$, indicating that the ability to activate $\mathrm{NF} K \mathrm{~B}$ correlates with the ability to escape. $\triangle b o p A C E$ formed less MNGCs compared to the rest, likely reflecting its lower replication ability.

Another possibility is that the $\triangle b s a M$ and $\triangle b o p A C E$ strains are defective in the secretion of T3SS3 effector proteins, which could be responsible for activating $\mathrm{NF}_{\kappa} \mathrm{B}$ as has been reported for the T3SS effector proteins SopE and SipA from Salmonella [25]. This is unlikely given that our single effector mutants could still activate $\mathrm{NFK}_{\mathrm{B}}$ as well as wildtype bacteria. To confirm, BopA (Figure 3A), BopC (Figure 3B) or BopE (Figure 3C) were ectopically expressed in increasing plasmid concentrations in HEK293T cells. None of the Burkholderia effectors were able to activate $\mathrm{NF}_{\kappa} \mathrm{B}$ significantly above background levels with the exception of BopE (Figure 3C), a homolog of Salmonella SopE, which showed only a slight activation. In contrast, expression of Salmonella SopE led to robust activation. We verified that the proteins were indeed expressed at the

\section{A}
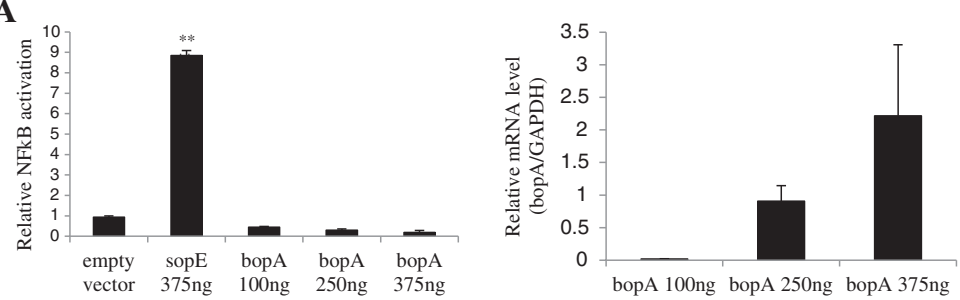

B
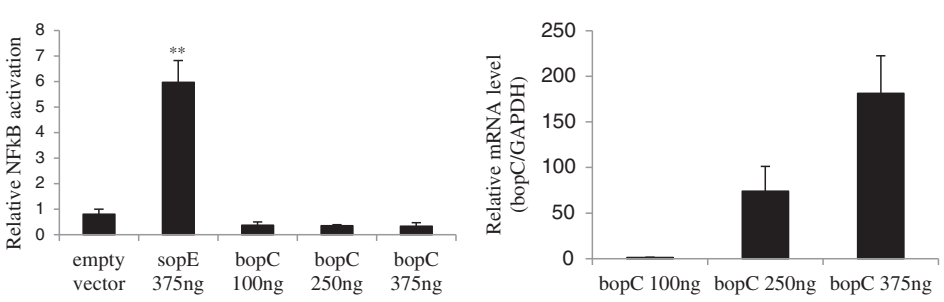

C

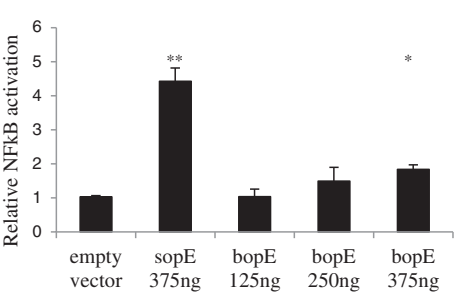

D
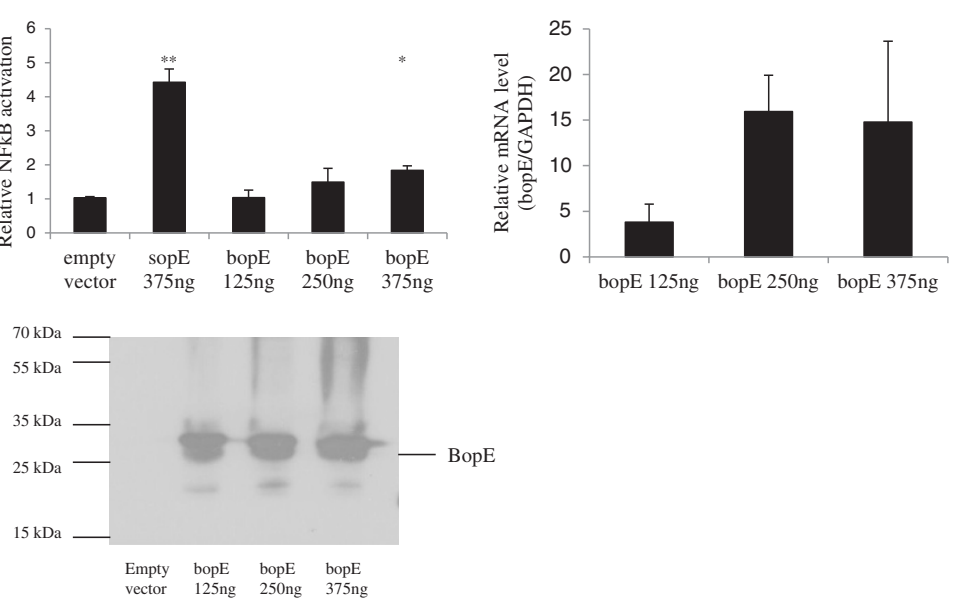

Figure 3 TLR independent NFKB activation by B. pseudomallei is not dependent on T3SS3 effectors. HEK293T cells were cotransfected with pNFKB-SEAP and mammalian expression vectors encoding genes for BopA (A) BopC (B) and BopE (C) for 24 hr. Supernatants were collected for SEAP assay (left panels). Total RNA was isolated for measuring of expression of effector genes (right panels) by real-time PCR. D) Cells transfected with BopE plasmid were lysed and analysed by Western blot with anti-BopE antibody. SopE was used as a positive control. Asterisks * and ** indicate significant differences of $p<0.05$ and $p<0.01$ between empty vector and plasmid expressing T3SS effector gene respectively. 
mRNA level (Figure 3A-C) as well as at the protein level for BopE (Figure 3D). It is therefore doubtful that individual T3SS3 effectors are responsible for NFкB activation in HEK293T cells, but that activation likely depends on T3SS3-mediated escape from endocytic vesicles following invasion.

\section{T3SS3 mutants activate NFKB when they gain access to the host cytosol}

It is known that T3SS3 facilitates escape from phagosomal or endosomal compartments into the host cell cytosol $[8,24]$, although $B$. pseudomallei T3SS3 mutants have been observed to exhibit delayed escape via an unidentified mechanism [8]. A time-course of NFKB activation shows that the T3SS3 mutant $\triangle b s a M$ was unable to activate $\mathrm{NFKB}$ at $6 \mathrm{hr}$. after infection, although it was increasingly able to do so when the incubation was extended to $24 \mathrm{hr}$. (Figure 4A), where levels became comparable to infection with wildtype KHW. In Figure 2C, we had shown that $\triangle b s a M$ mutant was unable to form MNGCs at $12 \mathrm{hr}$., corresponding to their inability to activate $\mathrm{NFK}_{\mathrm{K}}$ at early time-points. By $18 \mathrm{hr}$., both wildtype KHW and $\Delta b s a M$ mutant induced the formation of MNGCs (Figure 4B). On the basis of these observations, we hypothesized that T3SS-independent escape from endosomes is responsible for $\mathrm{NF \kappa B}$ activation by the $\triangle b s a M$ mutant at later time points, and the critical event required for NFkB activation is bacterial entry into the cytosol.
If $\mathrm{NFKB}$ activation at early time points results from rapid escape from the endosome, then direct placement of bacteria into the cytosol should obviate the need for T3SS-mediated escape. This was tested using a photothermal nanoblade, which allows us to bypass the need for invasion and endosome escape altogether $[24,26]$. The photothermal nanoblade utilizes a 6 ns pulse from a $540 \mathrm{~nm}$ laser to excite a titanium coating on glass micropipettes that are brought into contact with mammalian cell membranes. Rapid heating results in the formation of a vapour "nanobubble", creating a local, transient delivery portal in the membrane bilayer through which cargo can be introduced. The advantages of photothermal nanoblade compared to traditional microinjection are that variablysized particles - from molecules to bacteria - can be efficiently delivered into a wide range of cell types, and cell viability is maintained since physical puncturing does not occur.

B. thailandensis was used for these experiments since the instrument is not adapted for use in a BSL-3 environment. $B$. thailandensis encodes a T3SS apparatus $\left(\mathrm{T}_{3} \mathrm{SS}_{\mathrm{Bsa}}\right)$ that is highly homologous to B. pseudomallei T3SS3 and functions in an analogous manner [24,27]. Its intracellular growth and intercellular spread characteristics are comparable to B. pseudomallei, making it a useful surrogate for studying the Burkholderia intracellular life cycle. We first established that NFKB activation is dependent on $B$. thailandensis $\mathrm{T} 3 \mathrm{SS}_{\mathrm{Bsa}}$, as the T3SS $\mathrm{Bsa}$ mutant $\Delta b s a S$ [24] did

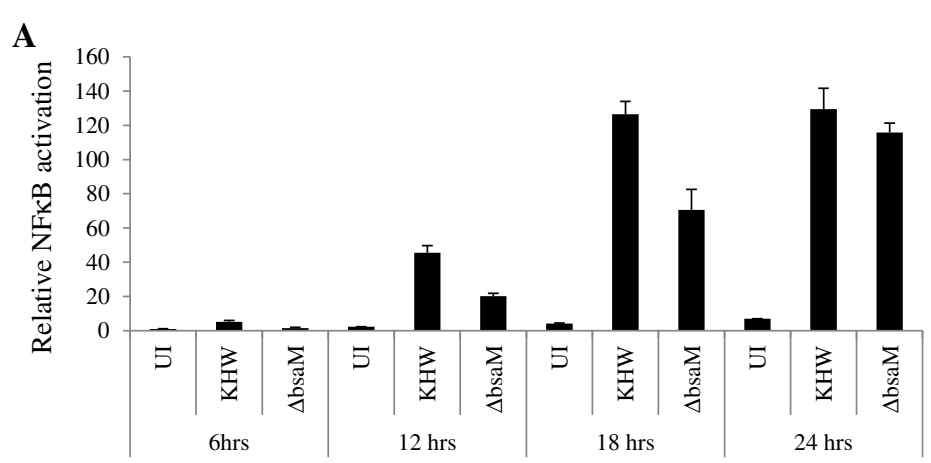

B

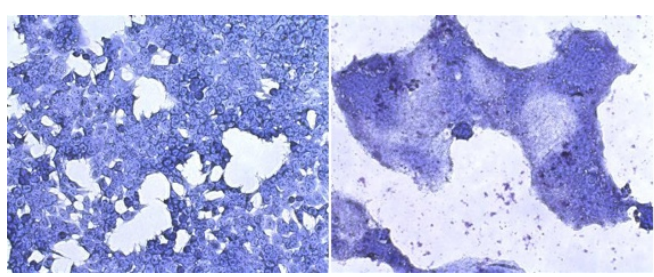

UI

KHW

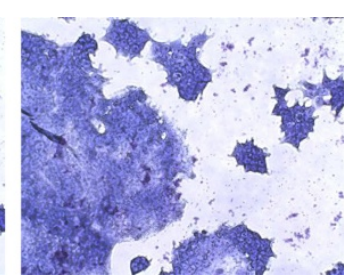

$\Delta \mathrm{bsaM}$

Figure 4 T3SS3 mutants activate NFKB at late time-points corresponding to escape into cytosol. A) HEK293T cells were transfected with pNFKB-SEAP for $24 \mathrm{hr}$. The transfected cells were infected with wildtype KHW and $\triangle b s a M$ at MOI of 10:1. Supernatants were collected at respective time points for SEAP assay. B) HEK293T cells were infected with wildtype KHW and $\triangle b s a M$ at MOI of 10:1 for $18 \mathrm{hr}$. The infected cells were fixed, stained with Giemsa and visualized under 10x magnification on a light microscope. 
not markedly activate NFKB at $6 \mathrm{hr}$. after infection at an MOI of 10:1 (Figure 5A), but did so at $24 \mathrm{hr}$. using the same MOI (Figure 5B), similar to what was seen with $B$. pseudomallei (Figure 4A). bsaS encodes the ATPase for T3SS $_{\text {Bsa }}$, and B. pseudomallei and B. thailandensis $\Delta b s a S$ derivatives have been shown to be deficient in $\mathrm{T}_{3 S S_{\text {Bsa }}}$ function, including lower intracellular replication [24]. PMA and ionomycin treatment served as positive controls for the photothermal nanoblade experiments, and NFKB /293/GFP-Luc cells were used so that NFkB activity could be measured by luciferase activity as well as GFP fluorescence. We were struck by the finding that $6 \mathrm{hr}$. after photothermal nanoblade delivery of bacteria into the host cell cytosol, both wildtype bacteria (Figure 6A) and the $\triangle$ bsaS mutant showed comparable GFP fluorescence and hence, NFKB activation (Figure 6B). Uninfected cells did not produce detectable GFP fluorescence (data not shown). Similarly, both the wildtype and $\Delta b s a S$ mutant bacteria activated $\mathrm{NF}_{\mathrm{K}} \mathrm{B}$ extensively at $24 \mathrm{hr}$. following nanoblade delivery (Figure 6C, D). Taken together, these results demonstrate that $\mathrm{T}_{3 \mathrm{SS}}$ Bsa mutants are able to activate NFkB effectively at early time-points if the need to escape from vacuolar compartments is bypassed by direct delivery of bacteria into the cytosol.

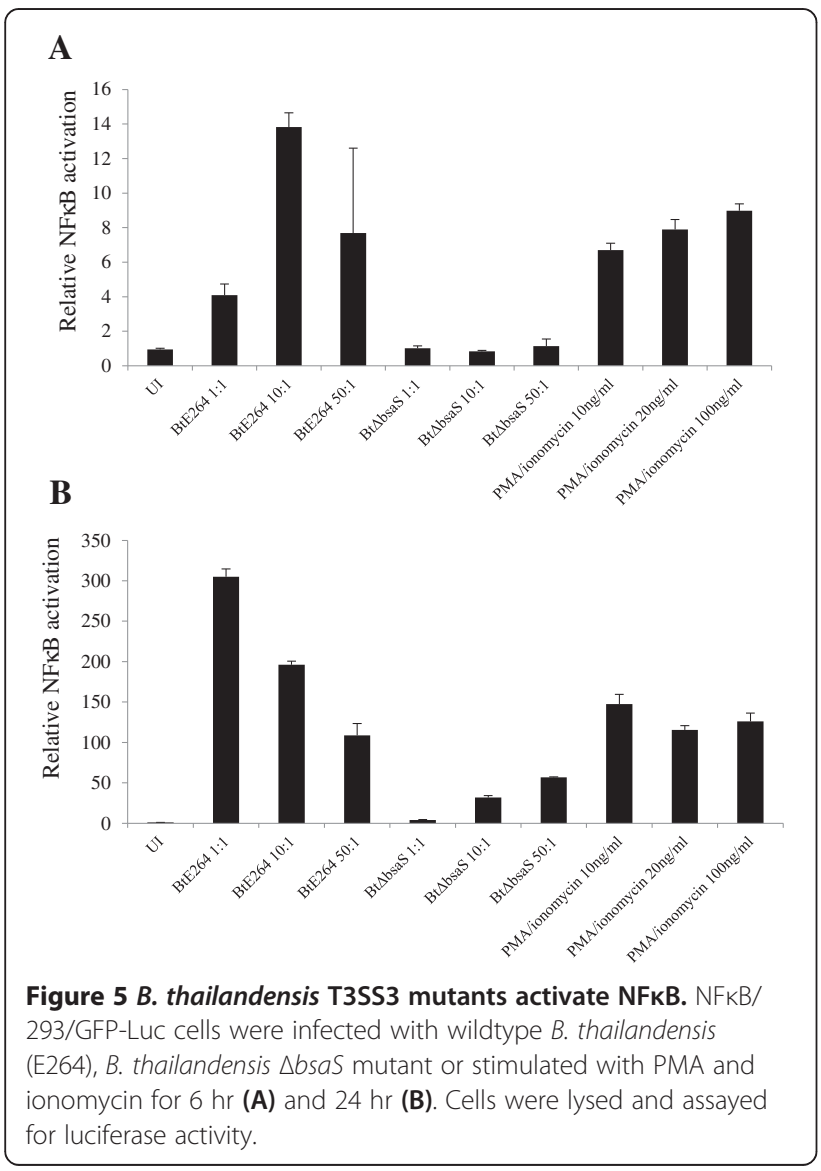

\section{B. pseudomallei stimulates activation of endogenous NFKB in HEK293T cells}

As previous experiments involved activation of an $\mathrm{NF}_{\mathrm{K}} \mathrm{B}$ reporter, we wanted to measure endogenous levels of NFkB activity in HEK293T cells infected with B. pseudomallei. To this end, we measured the phosphorylation of key $\mathrm{NF}_{\kappa} \mathrm{B}$ signalling intermediates beginning with the most downstream signalling molecule in the pathway, the NFкB p65 subunit. Infection of cells with wildtype bacteria, but not $\triangle \mathrm{T} 3 \mathrm{SS} 3$ or $\triangle b s a M$ mutants, led to a pronounced increase in phosphorylated p65, whereas total p65 remained constant at $2 \mathrm{hr}$. and $3 \mathrm{hr}$. post infection (Figure 7A). Phosphorylation of the central IкB $\alpha$ was also seen following infection with wildtype bacteria, but not with $B$. pseudomallei and B. thailandensis $\triangle b s a M$ mutants (Figure 7B). A key signalling intermediate in the NFKB activation pathway is TAK1, which lies upstream of the IKK complex and is triggered by various stimuli such as TNF $\alpha$, IL- $1 \beta$, TLRs, TGF $\beta$ and DNA damage [28]. We found that B. pseudomallei infection resulted in a time-dependent increase in phosphorylated TAK1 (Figure 7C), which was greatly reduced following infection with B. pseudomallei and B. thailandensis $\triangle b s a M$ mutants (Figure 7D). Thus, these experiments show that infection with wildtype bacteria, but not T3SS3-defective mutants, leads to endogenous NFkB activation accompanied by activation of TAK1, in agreement with our previous data with the $N F \kappa B$ reporter assays.

\section{Discussion}

Several Gram-negative bacterial pathogens capable of infecting epithelial cells possess secretion systems such as T3SS or T4SS that modulate NFkB signalling. In Legionella pneumophila, NFkB activation was shown to occur via a TLR dependent pathway, as well as a TLR-independent pathway that requires the $\mathrm{Icm} /$ Dot translocation system [29-32]. Recently, a Icm/Dot substrate LnaB has been identified to be responsible for TLR-independent activation of NFKB with activation of RIP2 (common downstream intermediate of NOD1 and NOD2) in HEK293T cells [33]. Another T4SS secreted effector, LegK1, activates NFkB directly by phosphorylating $\mathrm{NF} \kappa \mathrm{B}$ inhibitor $\mathrm{I} \kappa \mathrm{B} \alpha$, leading to downstream activation independent of host PRRs [34].

Intestinal pathogens such as Salmonella and Shigella have been shown to activate $\mathrm{NF}_{\mathrm{KB}}$ in intestinal epithelial cells in a TLR independent manner. For example, Shigella flexneri invades and activates NOD1, which senses bacterial peptidoglycan, leading to IL-8 production [35]. In Salmonella, the T3SS effector SopE activates NFkB [36] by engaging small Rho GTPases CDC42 and Rac1, which in turn trigger NOD1 and RIP2 activation of NFkB [25]. Another Salmonella T3SS effector protein SipA was also found to activate NFkB via NOD1/NOD2 


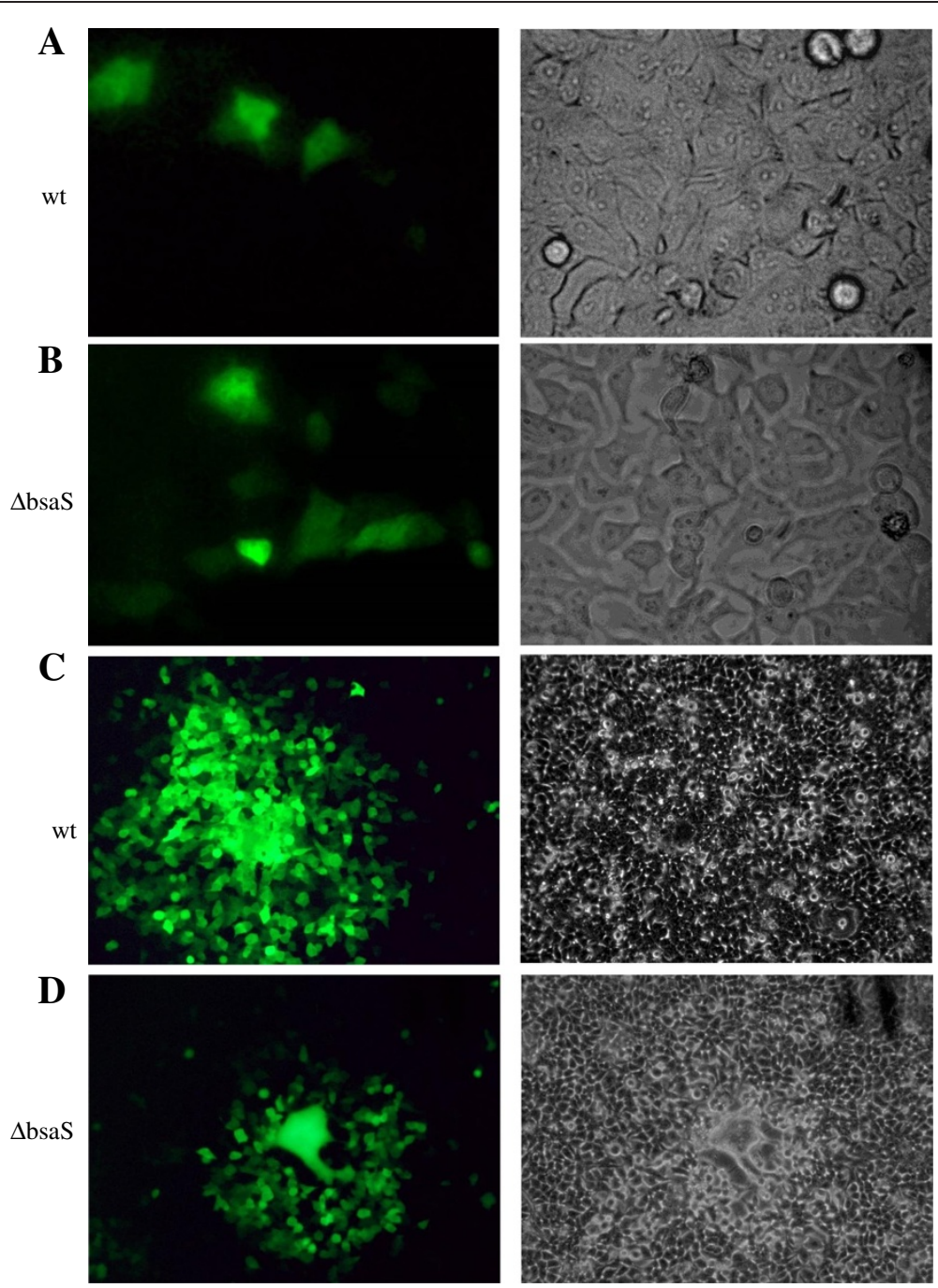

Figure 6 Direct delivery of T3SS3 mutant into the cytosol activates NFKB. NFKB/293/GFP-Luc cells were injected with wildtype B. thailandensis (E264) (A) or B. thailandensis $\triangle \mathrm{bsaS}$ (B) for $6 \mathrm{hr}$ or $24 \mathrm{hr}$ (C, D). The infected cells were observed under the fluorescence microscope (40x magnification for $6 \mathrm{hr}$ and 10x magnification for $24 \mathrm{hr}$ ) to monitor for GFP production as an indication of NFKB activation. The right panel represents an image taken under bright field microscope illumination whereas the left panel shows an image taken under fluorescence illumination.

signalling pathway that proceeds through RIP2 [37]. In contrast, it cannot be definitively determined in Yersinia whether the T3SS cargo or translocon pore is responsible for activating NFKB [13].

In this study, we have shown that $B$. pseudomallei and B. thailandensis T3SS3 do not directly activate $\mathrm{NF}_{\mathrm{KB}}$ in any significant way in HEK293T epithelial cells. T3SS3 is necessary for efficient escape of bacteria from endoso$\mathrm{mal} /$ phagosomal compartments into the cytosol at early time-points, although some escape may occur with low efficiency at later time-points independently of T3SS3 [8]. Although the direct delivery of T3SS3 mutants was done only with $B$. thailandensis, the time course of MNGC formation and NFkB activation of B. pseudomallei $\triangle b s a M$ mutants, and the similarity in various parameters between the two species in our experiments as well as what has been reported in the literature $[23,26]$ would support our conclusion. In contrast to what has been found for Salmonella, known T3SS3 effectors are not essential for NFKB activation by Burkholderia. This is supported by several lines of evidence: T3SS mutant bacteria exhibit delayed but significant $\mathrm{NF \kappa B}$ activation at later time-points, corresponding to their escape into the cytosol; overexpressed T3SS3 effectors do not activate $\mathrm{NF}_{\mathrm{K}} \mathrm{B}$; and direct delivery of bacteria into the cytosol via nanoblade injection obviates the need for T3SS3 in NFkB activation even at early timepoints. Thus, the key event triggering $\mathrm{NF}_{\kappa} \mathrm{B}$ activation is the presence of Burkholderia in the cytoplasm. We have not completely ruled out the possibility that unknown 


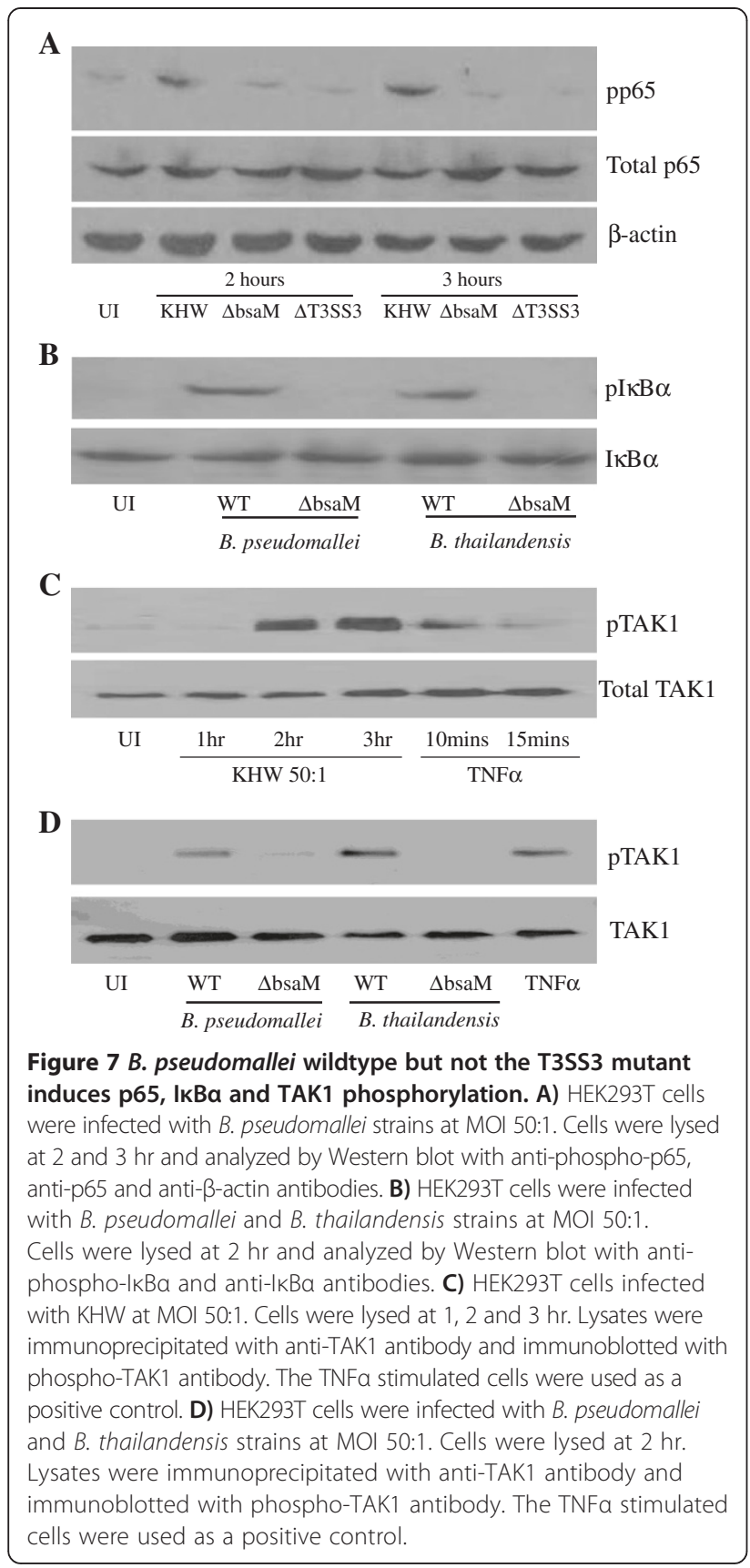

T3SS3 effectors secreted by other T3SSs in the absence of T3SS3 may partly be responsible for the NFKB activation we see, but even if this is true, it likely plays a minor role as the activation would not have depended so much on the cytosolic presence of the bacteria. The requirement for cytosolic presence of the pathogen likely reflects the host's reliance on cytosolic sensors to detect generic pathogen associated molecular patterns (PAMPs) rather than the specific recognition of T3SS- or T4SS-associated proteins as seen for pathogens that depend on survival within a vacuolar compartment such as Salmonella and Legionella. However, we cannot rule out the possibility that the cytosolic presence of bacteria expose T3SS3 structural components to activate $\mathrm{NF} \kappa \mathrm{B}$.

The detection of endogenous TAK1 activation in HEK293T cells following infection with wildtype, but not T3SS3 mutants, suggests the activation of the intracellular pattern recognition receptors (PRRs) NOD1 and NOD2, both of which signal through TAK1. B. pseudomallei is reportedly able to signal through NOD2 in RAW264.7 macrophages to upregulate suppressor of cytokine signalling 3 (SOCS3) although it does not result in similar upregulation of the proinflammatory cytokines TNF $\alpha$, IL- $1 \beta$ and IL- 6 which depend on activation of NFKB [38]. Recently, it is reported that NOD2 plays a minor role in murine melioidosis and a human genetic polymorphism in NOD2 region is associated with melioidosis [39]. It is possible that NOD1 and NOD2, which sense bacterial peptidoglycan derivatives IE-DAP and muramyl dipeptide respectively, may be the major cytosolic sensors responsible for NFKB activation.

\section{Conclusions}

Use of the HEK293T cells has allowed us to determine how Burkholderia T3SS3 contributes to NFkB activation in the absence of TLR and MyD88 signalling. We were able to discern that activation of NFKB does not occur as a direct consequence of Burkholderia T3SS3 secretion of effectors, but rather through cytosolic sensors that respond to the presence of bacteria in the cytosol following T3SS3-mediated escape from endocytic vesicles. Our study serves as a model for future work to identify the cytosolic sensors and the conditions leading to NFKB activation. It is possible that $\mathrm{NFKB}$ is not triggered efficiently by surface or endosomal PRRs, whereupon cytosolic sensors become important in establishing recognition of bacterial pathogens and eventual protection. Alternatively, the activation of these cytosolic sensors may lead to a different gene expression program that provides a regulatory function distinct from the TLR response.

\section{Methods}

\section{Cell-lines and bacterial strains}

Human embryonic kidney HEK293T (ATCC CRL-11268) cells were cultured in Dulbecco's modified Eagle medium (Sigma-Aldrich) with 10\% heat-inactivated fetal bovine serum (Life Technologies), 1X penicillin/streptomycin (Life Technologies) and $2 \mathrm{mM}$ L-glutamine (Life Technologies) at $37^{\circ} \mathrm{C}$ with humidified atmosphere with $5 \% \mathrm{CO}_{2}$. NFkB/ 293/GFP-Luc cell line was purchased from System Biosciences and cultured in the same medium as HEK293T cells. Bacterial strains used are listed in Table 1. 
Table 1 List of bacterial strains used in this study

\begin{tabular}{|c|c|c|}
\hline Strain & Relevant characteristic(s) $^{a}$ & $\begin{array}{l}\text { Source or } \\
\text { reference }\end{array}$ \\
\hline \multicolumn{3}{|c|}{ B. pseudomallei } \\
\hline KHW & B. pseudomallei wildtype strain & {$[40]$} \\
\hline$\triangle \mathrm{T} 3 \mathrm{SS} 1$ & $\begin{array}{l}\text { T3SS1 cluster was replaced with } \\
\text { tetracycline resistance gene, } T c^{r}\end{array}$ & [40] \\
\hline$\triangle \mathrm{T} 3 \mathrm{SS} 2$ & $\begin{array}{l}\text { T3SS2 cluster was replaced with } \\
\text { tetracycline resistance gene, } T c^{r}\end{array}$ & {$[40]$} \\
\hline$\triangle \mathrm{T} 3 \mathrm{SS} 3$ & $\begin{array}{l}\text { T3SS3 cluster was replaced with } \\
\text { zeocin gene, Zeor }\end{array}$ & {$[40]$} \\
\hline$\Delta b s a M$ & bsaM orf was deleted & This study \\
\hline$\triangle b o p A$ & $\begin{array}{l}\text { bopA orf was replaced with zeocin } \\
\text { resistance gene, Zeor }\end{array}$ & This study \\
\hline$\triangle b o p C$ & $\begin{array}{l}\text { bopC orf was replaced with zeocin } \\
\text { resistance gene, Zeor }\end{array}$ & This study \\
\hline$\triangle b o p E$ & bopE orf was deleted & This study \\
\hline$\triangle b o p A C E$ & $\begin{array}{l}\text { bopA and bopE orfs were deleted, } \\
\text { bopC orf was replaced with zeocin } \\
\text { resistance gene, Zeor }\end{array}$ & This study \\
\hline \multicolumn{3}{|c|}{ B. thailandensis } \\
\hline E264 & B. thailandensis wildtype strain & [41] \\
\hline$\Delta b s a S$ & bsas orf was deleted & [24] \\
\hline$\Delta b s a M$ & bsaM orf was deleted & This study \\
\hline
\end{tabular}

${ }^{a}$ Abbreviations: Tc $^{r}$, tetracycline resistant, Zeo ${ }^{r}$, zeocin resistant.

\section{Bacterial mutant construction}

All plasmids used for mutant construction are listed in Table 2. B. pseudomallei and B. thailandensis gene deletions were generated by allelic exchange. Approximately $1 \mathrm{~kb}$ fragments upstream and downstream of the target gene were amplified from genomic DNA and cloned into pK18mobsacB vector [42] simultaneously using InFusion PCR cloning kit (Clontech). A zeocin resistance cassette from pUC18T-mini-Tn7T-Zeo-lox [43] was inserted between the gene fragments for some of the constructions. The plasmids were introduced into $B$. pseudomallei and $B$. thailandensis strains by conjugation. Homologous recombination was then selected for by growing bacteria in $\mathrm{LB}+15 \%$ sucrose to counter select the $s a c B$ gene in the $\mathrm{pK} 18 \mathrm{mobsacB}$ plasmid backbone. Successful double cross-over clones were screened by colony PCR from kanamycin sensitive colonies. Primers used for mutant construction are listed in Table 3.

\section{Plasmid transfection and NFKB reporter assay}

HEK293T cells were seeded at a density of $1.25 \times 10^{5}$ cells/well in 24-well tissue culture plates and incubated for $24 \mathrm{hr}$. For measuring the activation of NFkB by $B$. pseudomallei wildtype (KHW) and mutants, the cells were transfected with $100 \mathrm{ng}$ of $\mathrm{pNF}$ B - SEAP plasmid using jetPRIME DNA \& siRNA transfection reagent (Polyplus Transfection). After another $24 \mathrm{hr}$., the media were replaced with antibiotics-free media. The cells were then infected with mid log-phase cultures of B. pseudomallei at required MOI. Following infection, plates were centrifuged at $200 \times \mathrm{g}$ for $5 \mathrm{~min}$ to allow maximum bacteria to cell contact. Two hr. post infection, $250 \mu \mathrm{g} / \mathrm{ml}$ kanamycin was added to kill off extracellular bacteria. Cells without infection were included as control. Supernatant was collected at various time points and SEAP activity was measured. For measuring the activation of NFkB by B. pseudomallei T3SS3 effectors, the cells were co-transfected with $100 \mathrm{ng}$ of $\mathrm{pNF} \kappa \mathrm{B}$-SEAP plasmid and up to $400 \mathrm{ng}$ of plasmid harbouring B. pseudomallei T3SS3 effector gene or $400 \mathrm{ng}$ of empty plasmid using jetPRIME DNA \& siRNA transfection reagent. Total amount of DNA transfected were kept constant at $500 \mathrm{ng}$. After another $24 \mathrm{hr}$., supernatant was collected and SEAP activity was measured. SEAP activity was measured using Phospha-Light kit (Life Technologies) according to the instructions of the manufacturer. Relative NFKB activation was calculated by averaging the raw luminescence values obtained using the Phospha-Light kit and converting them to fold activation with respect to uninfected cells or cells transfected with empty vector.

Table 2 Plasmids used for cellular transfection in the study

\begin{tabular}{|c|c|c|}
\hline Plasmid & Relevant characteristic(s) $^{a}$ & Source or reference \\
\hline pK18mobsacB & Conjugative, suicide vector containing sacB gene, $\mathrm{Km}^{\mathrm{r}}$ & {$[42]$} \\
\hline pUC18T-mini-Tn7T-Zeo-lox & Source of zeocin resistance gene, $\mathrm{Ap}^{r}, \mathrm{Zeo}^{\mathrm{r}}$ & {$[43]$} \\
\hline pNFKB-SEAP & Reporter vector containing NFKB enhancer element fused to SEAP gene, Amp ${ }^{R}$ & BD Clontech \\
\hline pcDNA3.1N5-His TOPO & Expression Vector, Amp ${ }^{R}$ & Life Technologies \\
\hline pCMV-FLAG-MAT-Tag-1 & Expression Vector, Amp ${ }^{R}$ & Sigma \\
\hline pcDNA-bopA & bopA gene cloned into pcDNA3.1/N5-His TOPO by TA-cloning, Amp ${ }^{R}$ & This study \\
\hline pCMV-bopC & bopC gene cloned into pCMV-FLAG-MAT-Tag-1, Amp ${ }^{R}$ & This study \\
\hline pRK5myc-BopE & bopE gene cloned into $\mathrm{pRK} 5 m y c, \mathrm{Amp}^{\mathrm{R}}$ & {$[23]$} \\
\hline pRK5myc-SopE & sopE gene cloned into pRK5myc, Amp ${ }^{R}$ & [23] \\
\hline
\end{tabular}

${ }^{a}$ Abbreviations: $\mathrm{Amp}^{\mathrm{R}}$, ampicillin resistant. 
Table 3 List of primers for this study

\begin{tabular}{|c|c|}
\hline Primer name & Sequences $\left(5^{\prime}-3^{\prime}\right)$ \\
\hline \multicolumn{2}{|l|}{$\begin{array}{l}\text { Mutant } \\
\text { construction }\end{array}$} \\
\hline BsaM up for & AAGCTTCACGCGACGCGATTITGAATTG \\
\hline BsaM up rev & AAGCTTGCTCGCCGACGCAGAAAAATA \\
\hline BsaM dn for & GAATTCAAGCTTGATCACGCGTCCTGGTATTT \\
\hline BsaM dn rev & TTGGATCCAAGCGAGACGTAGATGCTG \\
\hline BopA up for & CCAAGCTTGCATGCCTGCAGGTCTTGCTCTCGGTTGAAGG \\
\hline BopA up rev & GAGGATCCCCGGGTATGCATCGACATTGATCATCC \\
\hline BopA dn for & TACCCGGGGATCCTCGCATGAAGAACGCATGAAGA \\
\hline BopA dn rev & CCATGATTACGAATTCGATTCTTGTTGCTCCGATGC \\
\hline BopC up for & CCATGATTACGAATTCCCCGACCAGTTGAAGATGTC \\
\hline BopC up rev & GAGGATCCCCGGGTAGAACCAATGCCTAGCCTCAC \\
\hline BopC dn for & TACCCGGGGATCCTCCTGGGGTCGGTTTACATACG \\
\hline BopC dn rev & CCAAGCTTGCATGCCTGCAGGAGCATCGCGAATACGAACT \\
\hline BopE up for & CGGTACCCGGGGATCCAACAACCGCTCCTTCATCC \\
\hline BopE up rev & TCATGTCTTGCTCTCGGTTG \\
\hline BopE dn for & GAGAGCAAGACATGAGACGCTCGAAGCCACATAC \\
\hline BopE dn rev & GGCCAGTGCCAAGCTTGTATTACGAGTCGGGGCTGA \\
\hline Bt BsaM up for & GGCCAGTGCCAAGCTITTCCAGAAAAGCGAGCAAT \\
\hline $\begin{array}{l}\text { Bt BsaM up } \\
\text { rev }\end{array}$ & GGCGATAAATGGCCTGATTA \\
\hline Bt BsaM dn for & AGGCCATTTATCGCCGATCACGCGTCCTGGTATT \\
\hline $\begin{array}{l}\text { Bt BsaM dn } \\
\text { rev }\end{array}$ & CGGTACCCGGGGATCCAGCAGCGAGAAAGAAACGAA \\
\hline \multicolumn{2}{|l|}{$\begin{array}{l}\text { Expression in } \\
\text { mammalian } \\
\text { cells }\end{array}$} \\
\hline BopA for & GAGGAGTGGATGATCAATGTCG \\
\hline BopA rev & GTTCTTCATGCTGTCTTCAGGC \\
\hline BopC for & AAGCTTAAGATGCCGAGCATGACC \\
\hline BopC rev & GGATCCTCATGCGAGTGGGGTGTC \\
\hline \multicolumn{2}{|l|}{ Real-Time PCR } \\
\hline BopA RT for & TTCGTGCTGTTCGGGCTGA \\
\hline BopA RT rev & TCGATACTTGAGCTCGCCTGACTT \\
\hline BopC RT for & TACCGACGATCTCGTCAAAG \\
\hline BopC RT rev & GCGTTCAAGGAAGTTAAGCC \\
\hline BopE RT for & TCCTTCGCTTCGCTGAAGATCG [18] \\
\hline BopE RT rev & ATTCGGCCGGCAAGTCTACG [18] \\
\hline GAPDH for & CAATGACCCCTTCATTGACC [44] \\
\hline GAPDH rev & GTTCACACCCATGACGAACATG [44] \\
\hline
\end{tabular}

\section{Intracellular bacterial count}

HEK293T cells were seeded and infected as described above. Two hr. post infection, cells were washed twice with 1x PBS before addition of fresh culture medium with $250 \mu \mathrm{g} / \mathrm{ml}$ kanamycin. At respective time points, infected cells were washed with $1 \mathrm{x}$ PBS and lysed with
$0.1 \%(\mathrm{v} / \mathrm{v})$ Triton X-100. Serial dilutions were performed on the lysates and subsequently plated on TSA agar and incubated at $37^{\circ} \mathrm{C}$ for $48 \mathrm{hr}$. Colony counts were used to calculate bacterial loads.

\section{Cytotoxicity of B. pseudomallei against HEK293T cells} HEK293T cells $\left(1.25 \times 10^{5}\right.$ cells/well $)$ were seeded and grown overnight in a 24 well plate. Cells were infected with the indicated MOI. At 1 hour post infection, kanamycin $(250 \mu \mathrm{g} / \mathrm{ml})$ was added to kill extracellular bacteria. Cytotoxicity was measured at $6 \mathrm{hr}$. post infection by assaying for lactate dehydrogenase (LDH) release in the cell supernatants using a LDH Cytotoxity Detection Kit (Clontech).

\section{Multi-nucleated giant cell assay}

HEK293T cells were seeded at a density of $2.5 \times 10^{4}$ cells/well in a 24-well tissue culture plate and infected with log-phase bacteria at MOI 10:1. Two hr. post infection, kanamycin was added to kill off extracellular bacteria and at respective time points, cells were washed with 1xPBS and fixed with $100 \%$ methanol (Sigma-Aldrich) for $1 \mathrm{~min}$. Cells were then rinsed with water and air dried before the addition of 20x diluted Giemsa stain (SigmaAldrich) for $20 \mathrm{~min}$. After staining, cells were washed with water two times before they were air dried and examined under light microscope for MNGC formation.

\section{Cloning of full-length bopA, and bopC gene into mammalian expression vector}

The pcDNA3.1/V5-His TOPO (pcDNA3.1) TA Expression kit (Life Technologies) was used for cloning of full-length bopA for over-expression in mammalian systems. The bopA coding sequence including stop codon was included in the primer so that the products were not tagged. Amplified product was cloned into the linearized pcDNA3.1 vector according to manufacturer's protocol. The bopC was cloned into pCMV-FLAG-MAT-Tag-1 Expression Vector (Sigma) according to manufacturer's instruction. The primers for amplification of bopA and bopC are listed in Table 3.

\section{Measurement of B. pseudomallei effector gene expression by real-time PCR}

Total RNA was isolated from transfected HEK293T cells 24 hours post transfection using illustra RNAspin Mini Kit (GE Healthcare). cDNA was synthesized using $1 \mu \mathrm{g}$ of RNA and the First Strand cDNA Synthesis Kit (Thermo Scientific). Transcripts were quantified using iQ Cybr Green Supermix (Bio-Rad) in a Bio-Rad iQ5 machine. The expression of effector gene was normalized to housekeeping control gene gapdh. Real-time PCR primers are listed in Table 3. 


\section{Photothermal nanoblade delivery of bacteria}

Bacteria for photothermal nanoblade injection were prepared by culturing in low-salt L- broth at $\mathrm{pH} 5.8$ until log-phase and then washed $3 \mathrm{X}$ and resuspended in Hanks balanced salt solution (HBSS) at $10^{8}-10^{9} \mathrm{cfu} / \mathrm{mL}$. $1-2 \mu \mathrm{l}$ of the bacterial suspension was loaded into titanium-coated pulled-glass microcapillary pipettes. Photothermal nanoblade delivery was performed essentially as described $[24,26]$. Briefly, the pulsed laser system used was a Q-switched, frequency-doubled $\mathrm{Nd}$ : YAG laser (Minilite I, Continuum) operated at $532 \mathrm{~nm}$ wavelength and $6 \mathrm{~ns}$ pulsewidth. The laser beam was sent into the fluorescence port of an inverted microscope (AxioObserver, Zeiss) and then through the objective lens (40X, $0.6 \mathrm{NA})$, to generate a $260 \mu \mathrm{m}$-wide laser spot on the sample plane. The optimized laser intensity used for bacterial delivery was $180 \mathrm{~mJ} / \mathrm{cm}^{2}$. The excitation laser pulse was synchronized with a liquid delivery system (FemtoJet, Eppendorf) using an electronic switch. A pressure of $100-350 \mathrm{hPa}$ was used to deliver 1-2 $\mathrm{pl}$ of suspension per pulse. Approximately one bacterium was successfully delivered into a cell every two pulses. Following nanoblade delivery, cells were washed twice with HBSS before the addition of fresh medium with $250 \mu \mathrm{g} / \mathrm{mL}$ kanamycin [24,26].

\section{Immunoprecipitation}

HEK293T cells were first seeded in a 6 well plate at a density of $1 \times 10^{6}$ cells per well and then infected with the required strain the following day. At required time points, cells were lysed with lysis buffer $(50 \mathrm{mM}$ Tris pH 7.5, $0.1 \mathrm{mM}$ EGTA, $0.27 \mathrm{M}$ sucrose, $50 \mathrm{mM}$ sodium fluoride, $1 \mathrm{mM}$ sodium orthovanadate, $5 \mathrm{mM}$ sodium pyrophosphate, $1 \%$ Triton-100, protease inhibitor cocktail). Protein G sepharose beads (Sigma-Aldrich) were pre-incubated with total TAK1 antibody (kind gift from Dr. Peter Cheung, Nanyang Technological University, Singapore) before the cell lysates were mixed and incubated with the beads for $1 \mathrm{hr}$. at $4^{\circ} \mathrm{C}$ with shaking. Beads were then washed twice with lysis buffer and twice with wash buffer (50 mM Tris- $\mathrm{HCl} \mathrm{pH}$ 7.5, 0.27 M Sucrose, $0.1 \%$ 2-mercaptoethanol) before being boiled in SDSPAGE sample buffer. Samples were subsequently resolved on SDS-PAGE gels and transferred onto nitrocellulose membrane (Pall Life Sciences).

\section{Western blotting}

Cells were lysed with MPer mammalian protein extraction reagent (Thermo Scientific) supplemented with protease cocktail (Thermo Scientific). Proteins were then quantitated using Bradford reagent (Bio-Rad). Samples were boiled in SDS-PAGE sample buffer and $50 \mu \mathrm{g}$ (per lane) were resolved on an SDS-PAGE gel and transferred onto nitrocellulose membranes (Pall Life Sciences). The membranes were then blocked with 5\% BSA at room temperature for $1 \mathrm{hr}$. and probed with specific antibodies at $4^{\circ} \mathrm{C}$ overnight followed by secondary antibody antirabbit IgG, HRP-linked for $1 \mathrm{hr}$. at room temperature. Antibodies were obtained from Cell Signaling Technology except the $\beta$-actin antibody (Sigma-Aldrich). Blots were developed on film (Pierce Chemical) using ECL plus Western blotting substrate (Thermo Scientific).

\section{Statistical analysis}

NFKB reporter assays were performed in triplicates. Results were presented as mean \pm standard deviation. Student's t-test was used to find the significant differences between the means. The significant differences were reported as $p<0.05\left(^{*}\right)$ and $p<0.01\left(^{* *}\right)$.

\section{Competing interests}

The authors declare that they have no competing interests.

\section{Authors' contributions}

BET, CTF, YHG designed the experiments. BET, YC, IGJC and CTF performed the experiments. BET, YC, CTF, YHG analyzed the results. THW, ES, PYC and MAT set up the photothermal nanoblade experiments. YHG conceived the study and together with CTF and JFM wrote the manuscript. All authors read and approved the final manuscript.

\section{Acknowledgments}

We thank Mark P Stevens (Institute of Animal Health, UK) for the BopE and SopE expression plasmids and Peter Cheung (Nanyang Technological University) and Liu Xinyu (NUS) for technical advice on the TAK1 immunoprecipitations and Western blots. This work is funded by the Ministry of Education Tier 2 grant T208A3105, the National Medical Research Council grant NMRC/EDG/1052/2011 to YHG, the Defense Threat Reduction Agency (HDTRA1-11-1-0003) to JFM, the Pacific Southwest Regional Center of Excellence in Biodefense and Emerging Infectious Diseases (U54 A1065359) to JFM, the National Science Foundation CBET 0853500, ECCS 0901154, DBI-0852701 awards, University of California Discovery Biotechnology Award 178517, the National Institutes of Health Roadmap for Medical Research Nanomedicine Initiative PN2EY018228, NIH R21EB014456, and an Innovator Award from the Broad Stem Cell Research Center at UCLA.

\section{Author details}

${ }^{1}$ Department of Biochemistry, Yong Loo Lin School of Medicine, National University of Singapore, Singapore 117597, Singapore. ${ }^{2}$ Department of Microbiology, Immunology and Molecular Genetics, Los Angeles, CA 90095, USA. ${ }^{3}$ Department of Pathology and Laboratory Medicine, Los Angeles, CA 90095, USA. ${ }^{4}$ Department of Mechanical and Aerospace Engineering, Los Angeles, CA 90095, USA. ${ }^{5}$ California NanoSystems Institute, Los Angeles, CA 90095, USA. ${ }^{6}$ Broad Stem Cell Research Center, Los Angeles, CA 90095, USA. ${ }^{7}$ Jonsson Comprehensive Cancer Center, The University of California Los Angeles, Los Angeles, CA 90095, USA. ${ }^{8}$ Molecular Biology Institute, The University of California Los Angeles, Los Angeles, CA 90095, USA.

${ }^{9}$ Immunology Program, National University of Singapore, Singapore 117597, Singapore.

Received: 30 December 2013 Accepted: 25 April 2014 Published: 6 May 2014

\section{References}

1. Galyov EE, Brett PJ, DeShazer D: Molecular insights into Burkholderia pseudomallei and Burkholderia mallei pathogenesis. Annu Rev Microbiol 2010, 64:495-517.

2. Jones AL, Beveridge TJ, Woods DE: Intracellular survival of Burkholderia pseudomallei. Infect Immun 1996, 64(3):782-790.

3. Wiersinga WJ, Currie BJ, Peacock SJ: Melioidosis. N Engl J Med 2012, 367(11):1035-1044. 
4. Wiersinga WJ, van der Poll T, White NJ, Day NP, Peacock SJ: Melioidosis: insights into the pathogenicity of Burkholderia pseudomallei. Nat Rev Microbiol 2006, 4(4):272-282.

5. Stevens MP, Haque A, Atkins T, Hill J, Wood MW, Easton A, Nelson M, Underwood-Fowler C, Titball RW, Bancroft GJ, Galyov EE: Attenuated virulence and protective efficacy of a Burkholderia pseudomallei bsa type III secretion mutant in murine models of melioidosis. Microbiology 2004, 150(Pt 8):2669-2676.

6. Warawa J, Woods DE: Type III secretion system cluster 3 is required for maximal virulence of Burkholderia pseudomallei in a hamster infection model. FEMS Microbiol Lett 2005, 242(1):101-108.

7. Lee $Y H$, Chen $Y$, Ouyang $X$, Gan $Y H$ : Identification of tomato plant as a novel host model for Burkholderia pseudomallei. BMC Microbiol 2010, 10:28.

8. Burtnick MN, Brett PJ, Nair V, Warawa JM, Woods DE, Gherardini FC: Burkholderia pseudomallei type III secretion system mutants exhibit delayed vacuolar escape phenotypes in RAW 264.7 murine macrophages. Infect Immun 2008, 76(7):2991-3000

9. Stevens MP, Wood MW, Taylor LA, Monaghan P, Hawes $P$, Jones PW, Wallis TS, Galyov EE: An Inv/Mxi-Spa-like type III protein secretion system in Burkholderia pseudomallei modulates intracellular behaviour of the pathogen. Mol Microbiol 2002, 46(3):649-659.

10. Sun GW, Lu J, Pervaiz S, Cao WP, Gan YH: Caspase-1 dependent macrophage death induced by Burkholderia pseudomallei. Cell Microbio 2005, 7(10):1447-1458.

11. Miao EA, Mao DP, Yudkovsky N, Bonneau R, Lorang CG, Warren SE, Leaf IA, Aderem A: Innate immune detection of the type III secretion apparatus through the NLRC4 inflammasome. Proc Natl Acad Sci U S A 2010, 107(7):3076-3080.

12. Kwuan L, Adams W, Auerbuch V: Impact of host membrane pore formation by the Yersinia pseudotuberculosis type III secretion system on the macrophage innate immune response. Infect Immun 2013, 81(3):905-914

13. Auerbuch V, Golenbock DT, Isberg RR: Innate immune recognition of Yersinia pseudotuberculosis type III secretion. PLoS Pathog 2009, 5(12):e1000686.

14. Hapfelmeier S, Stecher B, Barthel M, Kremer M, Muller AJ, Heikenwalder M, Stallmach T, Hensel M, Pfeffer K, Akira S, Hardt WD: The Salmonella pathogenicity island (SPI)-2 and SPI-1 type III secretion systems allow Salmonella serovar typhimurium to trigger colitis via MyD88dependent and MyD88-independent mechanisms. J Immunol 2005, 174(3):1675-1685.

15. Girardin SE, Boneca IG, Carneiro LA, Antignac A, Jehanno M, Viala J, Tedin K, Taha MK, Labigne A, Zähringer U, Coyle AJ, DiStefano PS, Bertin J, Sansonetti PJ, Philpott DJ: Nod1 detects a unique muropeptide from gram-negative bacterial peptidoglycan. Science 2003, 300(5625):1584-1587.

16. Zhao L, Kwon MJ, Huang S, Lee JY, Fukase K, Inohara N, Hwang DH: Differential modulation of Nods signaling pathways by fatty acids in human colonic epithelial HCT116 cells. J Biol Chem 2007, 282(16):11618-11628.

17. Hii CS, Sun GW, Goh JW, Lu J, Stevens MP, Gan YH: Interleukin-8 induction by Burkholderia pseudomallei can occur without Toll-like receptor signaling but requires a functional type III secretion system. J Infect Dis 2008, 197(11):1537-1547.

18. Chen Y, Wong J, Sun GW, Liu Y, Tan GY, Gan YH: Regulation of type VI secretion system during Burkholderia pseudomallei infection. Infect Immun 2011, 79(8):3064-3073.

19. Sun GW, Gan YH: Unraveling type III secretion systems in the highly versatile Burkholderia pseudomallei. Trends Microbiol 2010, 18(12):561-568.

20. Tan KS, Chen Y, Lim YC, Tan GY, Liu Y, Lim YT, Macary P, Gan YH: Suppression of host innate immune response by Burkholderia pseudomallei through the virulence factor TssM. J Immunol 2010, 184(9):5160-5171.

21. Cullinane M, Gong L, Li X, Lazar-Adler N, Tra T, Wolvetang E, Prescott M, Boyce JD, Devenish RJ, Adler B: Stimulation of autophagy suppresses the intracellular survival of Burkholderia pseudomallei in mammalian cell lines. Autophagy 2008, 4(6):744-753.

22. Muangman $S$, Korbsrisate $S$, Muangsombut $V$, Srinon $V$, Adler NL, Schroeder GN, Frankel G, Galyov EE: BopC is a type III secreted effector protein of Burkholderia pseudomallei. FEMS Microbiol Lett 2011, 323(1):75-82.
23. Stevens MP, Friebel A, Taylor LA, Wood MW, Brown PJ, Hardt WD, Galyov EE: A Burkholderia pseudomallei type III secreted protein, BopE, facilitates bacterial invasion of epithelial cells and exhibits guanine nucleotide exchange factor activity. J Bacterio/ 2003, 185(16):4992-4996.

24. French CT, Toesca IJ, Wu TH, Teslaa T, Beaty SM, Wong W, Liu M, Schroder I, Chiou PY, Teitell MA, Miller JF: Dissection of the Burkholderia intracellular life cycle using a photothermal nanoblade. Proc Natl Acad Sci U S A 2011, 108(29):12095-12100.

25. Keestra AM, Winter MG, Auburger JJ, Frassle SP, Xavier MN, Winter SE, Kim A, Poon V, Ravesloot MM, Waldenmaier JF, Tsolis RM, Eigenheer RA, Bäumler AJ: Manipulation of small Rho GTPases is a pathogen-induced process detected by NOD1. Nature 2013, 496(7444):233-237.

26. Wu TH, Teslaa T, Kalim S, French CT, Moghadam S, Wall R, Miller JF, Witte ON, Teitell MA, Chiou PY: Photothermal nanoblade for large cargo delivery into mammalian cells. Anal Chem 2011, 83(4):1321-1327.

27. Haraga A, West TE, Brittnacher MJ, Skerrett SJ, Miller SI: Burkholderia thailandensis as a model system for the study of the virulenceassociated type III secretion system of Burkholderia pseudomallei. Infect Immun 2008, 76(11):5402-5411.

28. Dai L, Aye Thu C, Liu XY, Xi J, Cheung PC: TAK1, more than just innate immunity. IUBMB Life 2012, 64(10):825-834.

29. Abu-Zant A, Jones S, Asare R, Suttles J, Price C, Graham J, Kwaik YA: Antiapoptotic signalling by the Dot/lcm secretion system of $\mathrm{L}$. pneumophila. Cell Microbiol 2007, 9(1):246-264.

30. Bartfeld S, Engels C, Bauer B, Aurass P, Flieger A, Bruggemann H, Meyer TF: Temporal resolution of two-tracked NF-kappaB activation by Legionella pneumophila. Cell Microbiol 2009, 11(11):1638-1651.

31. Losick VP, Isberg RR: NF-kappaB translocation prevents host cell death after low-dose challenge by Legionella pneumophila. J Exp Med 2006 203(9):2177-2189.

32. Shin S, Case CL, Archer KA, Nogueira CV, Kobayashi KS, Flavell RA, Roy CR, Zamboni DS: Type IV secretion-dependent activation of host MAP kinases induces an increased proinflammatory cytokine response to Legionella pneumophila. PLoS Pathog 2008, 4(11):e1000220.

33. Losick VP, Haenssler E, Moy MY, Isberg RR: LnaB: a Legionella pneumophila activator of NF-kappaB. Cell Microbiol 2010, 12(8):1083-1097.

34. Ge J, Xu H, Li T, Zhou Y, Zhang Z, Li S, Liu L, Shao F: A Legionella type IV effector activates the NF-kappaB pathway by phosphorylating the IkappaB family of inhibitors. Proc Natl Acad Sci U S A 2009, 106(33):13725-13730.

35. Girardin SE, Tournebize R, Mavris M, Page AL, Li X, Stark GR, Bertin J, DiStefano PS, Yaniv M, Sansonetti PJ, Philpott DJ: CARD4/Nod1 mediates NF-kappaB and JNK activation by invasive Shigella flexneri. EMBO Rep 2001, 2(8):736-742

36. Bruno VM, Hannemann S, Lara-Tejero M, Flavell RA, Kleinstein SH, Galan JE: Salmonella Typhimurium type III secretion effectors stimulate innate immune responses in cultured epithelial cells. PLoS Pathog 2009, 5(8):e1000538

37. Keestra AM, Winter MG, Klein-Douwel D, Xavier MN, Winter SE, Kim A, Tsolis RM, Baumler AJ: A Salmonella virulence factor activates the NOD1/NOD2 signaling pathway. MBio 2011, 2(6):e00266-11.

38. Pudla M, Kananurak A, Limposuwan K, Sirisinha S, Utaisincharoen P: Nucleotide-binding oligomerization domain-containing protein 2 regulates suppressor of cytokine signaling 3 expression in Burkholderia pseudomallei-infected mouse macrophage cell line RAW 264.7. Innate Immun 2011, 17(6):532-540.

39. Myers ND, Chantratita N, Berrington WR, Chierakul W, Limmathurotsakul D, Wuthiekanun V, Robertson JD, Liggitt HD, Peacock SJ, Skerrett SJ, West TE: The Role of NOD2 in Murine and Human Melioidosis. J Immunol 2014, 192(1):300-307.

40. Liu B, Koo GC, Yap EH, Chua KL, Gan YH: Model of differential susceptibility to mucosal Burkholderia pseudomallei infection. Infect Immun 2002, 70(2):504-511.

41. Brett PJ, DeShazer D, Woods DE: Burkholderia thailandensis sp. nov., a Burkholderia pseudomallei-like species. Int J Syst Bacteriol 1998, 48(Pt 1):317-320.

42. Schafer A, Tauch A, Jager W, Kalinowski J, Thierbach G, Puhler A: Small mobilizable multi-purpose cloning vectors derived from the Escherichia coli plasmids pK18 and pK19: selection of defined deletions in the chromosome of Corynebacterium glutamicum. Gene 1994, 145(1):69-73. 
43. Choi KH, Mima T, Casart Y, Rholl D, Kumar A, Beacham IR, Schweizer HP: Genetic tools for select-agent-compliant manipulation of Burkholderia pseudomallei. Appl Environ Microbiol 2008, 74(4):1064-1075.

44. Koka V, Huang XR, Chung AC, Wang W, Truong LD, Lan HY: Angiotensin II up-regulates angiotensin I-converting enzyme (ACE), but down-regulates ACE2 via the AT1-ERK/p38 MAP kinase pathway. Am J Pathol 2008 172(5):1174-1183

doi:10.1186/1471-2180-14-115

Cite this article as: Teh et al:: Type three secretion system-mediated escape of Burkholderia pseudomallei into the host cytosol is critical for the activation of NFKB. BMC Microbiology 2014 14:115.

\section{Submit your next manuscript to BioMed Central and take full advantage of:}

- Convenient online submission

- Thorough peer review

- No space constraints or color figure charges

- Immediate publication on acceptance

- Inclusion in PubMed, CAS, Scopus and Google Scholar

- Research which is freely available for redistribution 